\title{
Short-Chain Acyl-Coenzyme A Dehydrogenase Deficiency
}

\author{
Clinical and Biochemical Studies in Two Patients
}

\author{
Brad A. Amendt," Carol Greene," Larry Sweetman," John Cloherty," Vivian Shih," \\ Anne Moon," Lisa Teel," and William J. Rhead* \\ ${ }^{*}$ Department of Pediatrics, University of Iowa, Iowa City, Iowa 52242; ${ }^{\ddagger}$ Department of Human Genetics, Tulane University School of \\ Medicine, New Orleans, Louisiana 70012; ' Department of Pediatrics, University of California, San Diego, La Jolla, California 92093; and \\ Departments of "Pediatrics and 'Neurology, Harvard Medical School, Boston, Massachusetts 02114
}

\begin{abstract}
We describe two patients with short-chain acyl-coenzyme $A$ (CoA) dehydrogenase (SCADH) deficiency. Neonate I excreted large amounts of ethylmalonate and methylsuccinate; ethylmalonate excretion increased after a medium-chain triglyceride load. Neonate II died postnatally and excreted ethylmalonate, butyrate, 3-hydroxybutyrate, adipate, and lactate. Both neonates' fibroblasts catabolized $\left[1-{ }^{14} \mathrm{C}\right]$ butyrate poorly $(29-64 \%$ of control). Neonate I had moderately decreased $\left[1-{ }^{14} \mathrm{C}\right]$ octanoate catabolism (43-60\% of control), while neonate II oxidized this substrate normally; both catabolized radiolabeled palmitate, succinate, and/or leucine normally. Cell sonicates from neonates I and II dehydrogenated $\left[2,3-{ }^{3} \mathrm{H}\right]$ butyryl-CoA poorly (41 and $53 \%$ of control) and $\left[2,3-{ }^{3} \mathrm{H}\right]$ octanoyl-CoA more effectively (59 and $95 \%$ of control). Mitochondrial acyl-CoA dehydrogenase (ADH) activities with butyryl- and octanoyl-CoAs were 37 and 56\% of control in neonate I, and 47 and $81 \%$ of control in neonate II, respectively. Monospecific medium-chain ADH (MCADH) antisera inhibited MCADH activity towards both butyryl- and octanoyl-CoAs, revealing SCADH activities to be 1 and $11 \%$ of control for neonates I and II, respectively. Fibroblast SCADH and MCADH activities were normal in an adult female with muscular SCADH deficiency.
\end{abstract}

\section{Introduction}

Deficiencies of the acyl-coenzyme A $(\mathrm{CoA})^{1}$ dehydrogenases $(\mathrm{ADH})$ have only recently been identified in man. Patients with medium-chain acyl-CoA dehydrogenase (MCADH) deficiency

Preliminary results from this paper have appeared in abstract form (1984. Am. J. Hum. Genet. 36:55; and 1984. Pediatr. Res. 19:309A).

Address reprint requests to Dr. Rhead, Dept. of Pediatrics, University of Iowa, Iowa City, IA 52242. 1986

Received for publication 8 July 1986 and in revised form 30 December

1. Abbreviations used in this paper: $\mathrm{ADH}$, acyl-CoA dehydrogenase; CoA, coenzyme A; ETF, electron-transfer flavoprotein; FAD, flavin adenine dinucleotide; LCADH, long-chain acyl-CoA dehydrogenase; LCD, long-chain acyl-CoA dehydrogenase deficiency; MAD, multiple acylCoA dehydrogenation disorders; MCADH, medium-chain acyl-CoA dehydrogenase; MCD, medium-chain acyl-CoA dehydrogenase deficiency; MCT, medium-chain triglycerides; SCADH, short-chain acylCoA dehydrogenase; SCD, short-chain acyl-CoA dehydrogenase deficiency.

J. Clin. Invest.

(C) The American Society for Clinical Investigation, Inc.

0021-9738/87/05/1303/07 \$1.00

Volume 79, May 1987, 1303-1309
(MCD) often present with episodes of hypoketotic hypoglycemia and medium-chain dicarboxylic aciduria, although both sudden, unexpected death and clinical normalcy have been observed in homozygotes (1). The presentation of long-chain acyl-CoA dehydrogenase (LCADH) deficiency (LCD) may also include hypotonia, hypertrophic cardiomyopathy, and early death (2). Short-chain acyl-CoA dehydrogenase (SCADH) deficiency (SCD) has recently been found in muscle from a patient with lipid storage myopathy (3) and proposed in a second patient excreting ethylmalonate whose fibroblasts poorly oxidized shortchain fatty acids (4).

We describe here two unrelated patients, both of whom presented with neonatal metabolic acidosis and ethylmalonate excretion. These observations suggested defective short-chain acylCoA dehydrogenation, since ethylmalonic and methylsuccinic acids can be formed from accumulated intramitochondrial butyryl-CoA. Butyryl-CoA is carboxylated by propionyl-CoA carboxylase to form ethylmalonyl-CoA, which is either hydrolyzed to ethylmalonic acid or converted to methylsuccinyl-CoA by methylmalonyl-CoA mutase, yielding in both cases methylsuccinic acid on hydrolysis $(5,6)$. Although these metabolites have been noted in patients with other inborn errors of metabolism, notably the multiple acyl-CoA dehydrogenation disorders (MAD; references 5-7), prominent excretion of ethylmalonate in our patients suggested SCADH deficiency. This enzyme catalyzes the first step in the $\beta$-oxidation of short-chain (4 and 6 carbon chain length fatty acids $\left[\mathrm{C}_{4}-\mathrm{C}_{6}\right]$ ) fatty acyl-CoAs.

This report summarizes clinical and biochemical studies on these SCD patients, the first in whom the defect is detected in fibroblasts. We demonstrated SCADH deficiencies by both an electron-transfer flavoprotein (ETF)-linked dye-reduction assay (8) and a tritium release ADH assay using [2,3- $\left.{ }^{3} \mathrm{H}\right]$ acyl-CoAs as substrates (9). The SCD patient described by Turnbull et al. (3) has normal SCADH activity in fibroblasts, which raises the possibility that a distinct SCADH isoenzyme exists in mammalian muscle.

\section{Methods}

\section{Case histories}

NEONATE I (L.N.)

This female was born at $6 \mathrm{lb} 14 \mathrm{oz}$ after a full-term uncomplicated pregnancy to a healthy 33 -yr-old mother with one living child. Delivery was assisted with forceps after an episode of deceleration. Apgar scores were 9 and 9 at 1 and $5 \mathrm{~min}$ and there was meconium staining of skin and cord. No problems were noted in the nursery. The parents were not consanguineous and there was no family history suggestive of metabolic or other genetic disorders. The infant was breast fed from birth. At age $6 \mathrm{~d}$, after a 3-d history of poor feeding and listlessness and $1 \mathrm{~d}$ of hyperpnea, she was found to be lethargic and admitted to the Stanford University Neonatal Intensive Care Unit with a heart rate of $180 \mathrm{bpm}$, 
temperature $36.5^{\circ} \mathrm{C}$, blood pressure normal, and extremities pale and mottled. The infant had poor skin turgor, sunken eyes, and fontanelle. Laboratory data (normal values in parentheses) was arterial $\mathrm{pH} 7.03$ (7.35-7.45 pH), with calculated $\mathrm{HCO}_{3} 3 \mathrm{meq} / \mathrm{liter}$ (22-26 meq/liter); $\mathrm{Na}, 166 \mathrm{meq} / \mathrm{liter}$ (135-145 meq/liter); K, $5.8 \mathrm{meq} / \mathrm{liter}$ (3.5-5.0 meq/ liter); and glucose, $94 \mathrm{mg} / 100 \mathrm{ml}(65-110 \mathrm{mg} / 100 \mathrm{ml}) .2 \mathrm{~h}$ later bloodurea nitrogen was $51 \mathrm{mg} / 100 \mathrm{ml}(10-20 \mathrm{mg} / 100 \mathrm{ml})$, creatinine $1.3 \mathrm{mg} /$ $100 \mathrm{ml}(0.7-1.4 \mathrm{mg} / 100 \mathrm{ml})$, and anion gap $31 \mathrm{meq} / \mathrm{liter}(10-15 \mathrm{meq} /$ liter). Urine $\mathrm{pH}$ was 6.5 , with ketones negative, trace reducing substances and small glucose. Complete blood count showed a leukocyte count of $21,400(4,800-10,100)$ with 62 polymorphonucleocytes $(42-81$ polymorphonucleocytes), 10 bands ( $0-6$ bands), $14.4 \mathrm{~g} /$ liter hemoglobin (15$24 \mathrm{~g} /$ liter $)$, and 655,000 platelets ( $150,000-400,000$ platelets); evaluation for infection, including blood, urine, spinal fluid cultures, and chest radiograph, were all normal. Samples of urine for amino and organic acids were obtained at admission.

Urine amino acids showed mild elevations of aspartate, threonine, glutamine, proline, glycine, alanine, and histidine (data not shown). Organic acids revealed highly elevated ethylmalonic acid (Table I), moderately elevated lactate $(2.85 \mu \mathrm{mol} / \mathrm{mg}$ creatinine; normal: $0.17-1.79$ $\mu \mathrm{mol} / \mathrm{mg})$, and decreased citric acid $(1.62 \mu \mathrm{mol} / \mathrm{mg}$ creatinine; normal: $2.06-15.18 \mu \mathrm{mol} / \mathrm{mg}$ ). The presence of antibiotic metabolites prevented further analysis. The infant responded to therapy with intravenous fluids, glucose, and bicarbonate. By the 5th day of hospitalization, feedings were begun and she tolerated increases to a regular diet of breast milk without recurrence of signs or symptoms of acidosis. A repeat urine 2 wk after presentation continued to show highly elevated ethylmalonic and methylsuccinic acids with normal adipic and without detectable glutaric, suberic, sebacic, azelaic, or hydroxydecanedioic acids. Over the next 4 mo she gained weight and attained developmental milestones normally while on a breast milk and soy formula diet.

To elucidate the nature of her metabolic block, a series of challenges with leucine, lysine, medium-chain triglycerides (MCT), and glycine was proposed. In the MAD (5-7), isovaleric, glutaric, and medium-chain dicarboxylic acid excretion would be expected to rise after challenges with the first three precursors, respectively. In MCD, only the MCT challenge would provoke a dicarboxylic aciduria. Concomitant glycine administration may promote excretion of specific acyl-glycines derived from accumulated acyl-CoAs and aid identification of the pathways involved $(5,10)$. After informed parental consent, these challenges were undertaken under controlled circumstances and were clinically uneventful, without any changes in monitored blood glucoses and pHs. The challenges, adapted from a protocol kindly supplied by Dr. W. Nyhan, Department of Pediatrics, University of California, San Diego, were performed in two sets, first with MCT with and without glycine, then with lysine and leucine. MCT (150 mg/kg per dose) was given t.i.d. for $1 \mathrm{~d}$ with concurrent evaluation of urine organic acids. On the 2 nd and 3 rd day glycine $(83 \mathrm{mg} / \mathrm{kg}$ per dose t.i.d.) was given, and continued on the 4th day with MCT $(150 \mathrm{mg} / \mathrm{kg}$ per dose t.i.d.), while urine organic acids were followed daily. The second set of challenges followed a 1-wk rest and repeat baseline studies. Lysine $(60 \mathrm{mg} / \mathrm{kg}$ per dose) was given t.i.d. for $2 \mathrm{~d}$ and was followed by analysis for urinary organic acids. After a $1-\mathrm{d}$ rest and a repeat baseline sample for organic acids, leucine $(100 \mathrm{mg} /$ $\mathrm{kg}$ ) was given in a single dose, and there was evaluation of plasma amino acids and urine organic acids at 2 and $6 \mathrm{~h}$, respectively. Nonvolatile urinary organic acids were analyzed by sequential liquid partition chromatography, gas chromatography, and gas chromatography-mass spectrometry as previously described (11). Results are shown in Table I.

Ethylmalonic and methylsuccinic acid excretions were elevated in all samples. Ethylmalonate elevation was most marked after the MCT and lysine challenges. Glycine alone resulted in decreased excretion of ethylmalonic acid without significant change in methylsuccinic acid, but did not prevent the increase in ethylmalonic acid after MCT challenge. No significant elevations of adipic, suberic, sebacic, or glutaric acids were noted, and metabolites of the branched chain amino acids (isovaleric, $\alpha$-methylbutyric, and isobutyric) were not excreted (other data not shown). This child has continued to show normal growth and development without clinical evidence of acidosis up to the age of $2 \mathrm{yr}$; the parents have refused further clinical studies or metabolite analyses involving their child.

NEONATE II (A.A.)

This female was born to a white female at $39 \mathrm{wk}$ of gestation. The pregnancy was uneventful except for a history of nausea, vomiting, and diarrhea of viral origin in the mother and her family in the month before this birth. The mother was of Italian and Portuguese extraction and the father of French Canadian extraction; they have five normal male children.

The baby was born by spontaneous vaginal delivery while the mother was under local anesthesia with Apgar scores of 9 and 9 at 1 and 5 min, respectively. The baby had a normal physical examination, and cow's milk formula feeding was started on day 2 . On the 3 rd day, the baby fed poorly, began to vomit, became lethargic and hypertonic. The respiratory rate was 60 and the liver extended $3 \mathrm{~cm}$ below the right costal margin. The rest of the exam was normal.

Laboratory tests included (normal values in parentheses): blood sugar, $38 \mathrm{mg} / 100 \mathrm{ml}(65-110 \mathrm{mg} / 100 \mathrm{ml}$; subsequently normal on intravenous glucose); bilirubin, $8 / 0.9 \mathrm{mg} / 100 \mathrm{ml}(0.2-1.0 / 0-0.2 \mathrm{mg} / 100 \mathrm{ml}$; serum glutamic oxaloacetic transaminase, 93 IU/liter (22-100 IU/liter); lactic dehydrogenase, 1,050 IU/liter (88-196 IU/liter); serum glutamic pyruvic transaminase, $50 \mathrm{IU} /$ liter (5-35 IU/liter); blood-urea nitrogen, $9 \mathrm{mg} /$ $100 \mathrm{ml}(10-20 \mathrm{mg} / 100 \mathrm{ml})$; complete blood count normal, arterial $\mathrm{pH}$

Table I. Urinary Levels of Organic Acids in Neonate I

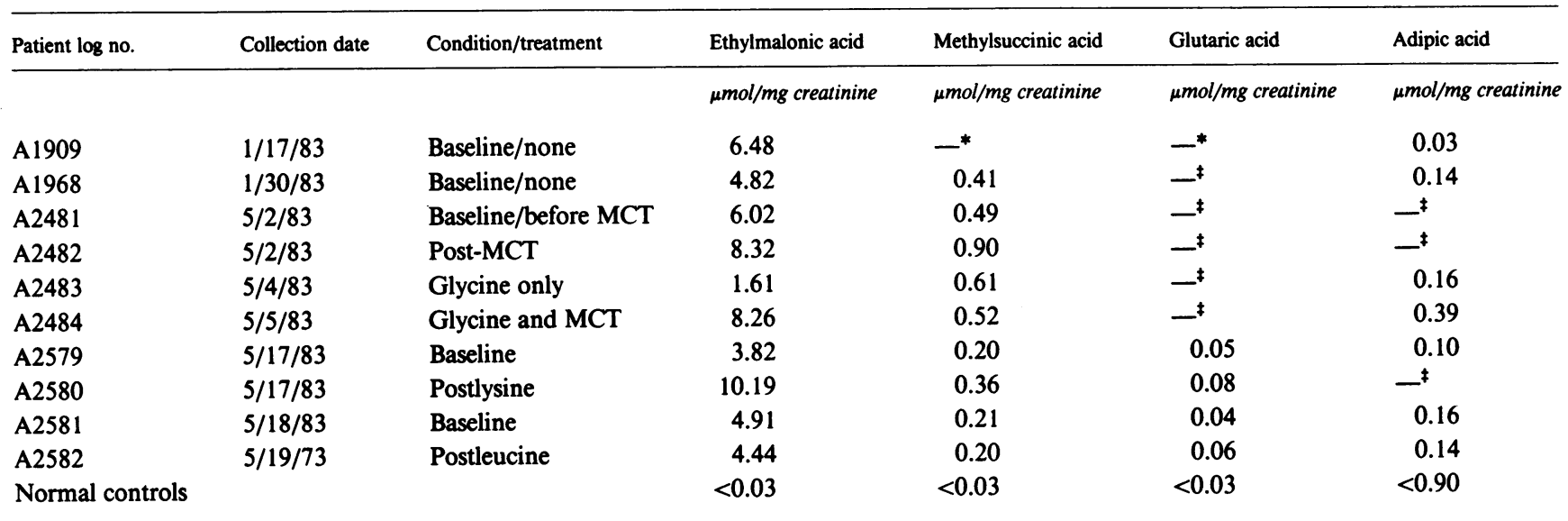

\footnotetext{
* Medication metabolites prevented quantitating these compounds.

$¥$ Not detected.
} 
7.28 (7.35-7.45 pH); $\mathrm{CO}_{2}, 26 \mathrm{meq} / \mathrm{liter}$ (22-26 meq/liter); $\mathrm{NH}_{3}, 399$ $\mu \mathrm{M}(7-42 \mu \mathrm{M})$; prothrombin time, $16.4 / 12.2 \mathrm{~s}(10-14 \mathrm{~s})$; and partial thromboplastin time, $33.4 \mathrm{~s}(24-35 \mathrm{~s})$. After $12 \mathrm{~h}$ of intravenous glucose nutrition alone, serum glutamic oxaloacetic transaminase was $211 \mathrm{IU} /$ liter, serum glutamic pyruvic transaminase 77 IU/liter, $\mathrm{NH}_{3} 298 \mu \mathrm{M}$, and the metabolic acidosis was unchanged. Bacterial and viral cultures of blood, urine, and spinal fluid were negative, and viral cultures from the mother's cervix and rectum were negative.

The baby was treated with penicillin and gentamicin and received only high dose intravenous glucose for nutrition. In spite of stable blood glucose, $\mathrm{NH}_{3}$, and arterial $\mathrm{pH}$, the baby became progressively more lethargic, unresponsive to noxious stimuli, hypotonic, and had worsening respiratory effort. An electroencephalogram showed multifocal seizures with poor background activity. The baby was given diphenylhydantoin and respiratory support. There was no clinical or laboratory response to intravenous riboflavin. Because of the metabolic acidosis and the elevated $\mathrm{NH}_{3}$, metabolic studies were performed on day 3 in Dr. Shih's laboratory. Organic acid screening by gas chromatography showed increased amounts of the following acids (listed in the order of decreasing amounts; no quantitation available): lactate, 3-hydroxybutyrate, butyrate, ethylmalonate, adipate, 2-hydroxybutyrate, and 3-hydroxyisovalerate. Glutarate and methylsuccinate were not increased. Amino acid screening of blood and urine revealed nonspecific generalized increases. Urine orotic acid excretion was normal.

On day 5 , the electroencephalogram was worse, a brain scan showed little blood flow, the baby had fixed dilated pupils, and had no spontaneous activity or response to stimuli. With the family's permission, biopsies were taken of liver and skin and support was discontinued on the 6th day of life. Portmortem exam showed cerebral edema, hepatomegaly with fatty changes (microvesicular fat, intracanalicular cholestasis, and focal hepatocellular necrosis), thymic involution, and early bronchopneumonia. Bacterial and viral cultures were negative.

Chemicals. $\left[1-{ }^{14} \mathrm{C}\right]$ Butyric acid (n-butanoic acid; $10 \mathrm{mCi} / \mathrm{mmol}$ ), [1$\left.{ }^{14} \mathrm{C}\right]$ octanoic acid $(10 \mathrm{mCi} / \mathrm{mmol}),\left[1,4-{ }^{14} \mathrm{C}\right]-$ and $\left[2,3-{ }^{14} \mathrm{C}\right]$ succinic acid $(1 \mathrm{mCi} / \mathrm{mmol})$, and $\left[9,10(n)-{ }^{3} \mathrm{H}\right]$ palmitate $(280 \mathrm{mCi} / \mathrm{mmol})$ were obtained from New England Nuclear, Boston, MA, or from Research Products Int'l., Arlington Heights, IL, and were diluted with cold carrier to the specific activities indicated below. $\left[2,3-{ }^{3} \mathrm{H}\right]$ Butyric, -octanoic, and -isovaleric acids were synthesized by New England Nuclear; the corresponding acyl-CoA esters were synthesized by the mixed anhydride method described previously (12). Phenazine methosulfate (5-methylphenazinium methyl sulfate), flavin adenine dinucleotide (FAD; riboflavin 5'-adenosine diphosphate), and $N$-ethylmaleimide were purchased from Sigma Chemical Co., St. Louis, MO. Pure pig liver MCADH, SCADH, and ETF were gifts from Dr. Carole L. Hall, Georgia Institute of Technology, Atlanta, GA; the pure pig kidney MCADH used for antisera preparation was a gift from Dr. Colin Thorpe, University of Delaware, Newark, DE.

Culture of fibroblasts. Skin fibroblasts were obtained from these two neonates and from six normal male infants. Fibroblasts were cultured in Eagle's minimal essential medium, and supplemented with $10 \%$ fetal bovine serum, $2 \mathrm{mM}$ glutamine, $140 \mu \mathrm{M}$ penicillin, and $86 \mu \mathrm{M}$ streptomycin. Fibroblasts were subcultured 1:4 every 2 wk and the media changed weekly. Fibroblasts of passage 6 to 20 were used in all experiments.
Oxidation studies. ${ }^{14} \mathrm{C}$-Labeled substrate oxidation to ${ }^{14} \mathrm{CO}_{2}$ by intact fibroblasts in suspension was performed as described earlier $(6,8)$. For neonate I's studies, the specific activities and concentrations of [1$\left.{ }^{14} \mathrm{C}\right]$ butyrate, -octanoate, -palmitate, and $\left[1,4-{ }^{14} \mathrm{C}\right]$ succinate were $10 \mathrm{mCi} /$ $\mathrm{mmol}, 1 \mathrm{mM} ; 4.7 \mathrm{mCi} / \mathrm{mmol}, 1 \mathrm{mM}, 5 \mathrm{mCi} / \mathrm{mmol}, 0.2 \mathrm{mM}$; and 1 $\mathrm{mCi} / \mathrm{mmol}, 2 \mathrm{mM}$, respectively. For neonate II's studies, specific activities and concentrations of $\left[1-{ }^{14} \mathrm{C}\right]$ butyrate and -octanoate were $1.86 \mathrm{mCi} /$ $\mathrm{mmol}, 1 \mathrm{mM}$, and $1 \mathrm{mCi} / \mathrm{mmol}, 2 \mathrm{mM} .{ }^{14} \mathrm{C}$-Incorporation from labeled substrates into cellular protein was performed as described previously, using ${ }^{14} \mathrm{C}$-labeled substrates at previously reported specific activities and concentrations (13). $\left[{ }^{3} \mathrm{H}\right]$ Palmitate oxidation to ${ }^{3} \mathrm{H}_{2} \mathrm{O}$ by fibroblast monolayers was performed as described previously (14).

ADH and ETF assays. Both fibroblast mitochondrial and cellular sonic supernatants were prepared by the methods described earlier $(8$, 9). The dye reduction ADH and ETF assays in mitochondrial supernatants and tritium release ADH assays in cell supernatants were described previously $(7-9,15)$. Electrophoretically and chromatographically pure pig kidney MCADH was isolated by Dr. Colin Thorpe, University of Delaware as previously described (16), and supplied to us for antiserum production. Primary immunization was with $700 \mu \mathrm{g}$ MCADH in an emulsion of Freund's complete adjuvant; a secondary immunization with $600 \mu \mathrm{g}$ MCADH in Freund's incomplete adjuvant was performed after $4 \mathrm{wk} .4 \mathrm{wk}$ later, the rabbit was exsanguinated by cardiac puncture and the serum separated and frozen at $-70^{\circ} \mathrm{C}$ until used. This antiserum preparation completely inhibited pure pig liver and kidney MCADHs and MCADH activity towards octanoyl-CoA in human fibroblast and mitochondrial supernatants, but did not inhibit the dehydrogenation of butyryl-CoA by pure pig liver SCADH (Table II; other data not shown). Nonimmune rabbit serum did not inhibit any SCADH or MCADH preparation (data not shown). The estimate of variance used is the standard error of the mean. Means were compared with the Student's $t$ test; all $P$ values given are two-tailed and compare the patients' data to the respective control values, unless stated otherwise.

\section{Results}

Fibroblast catabolism of radiolabeled substrates. Fibroblasts from both neonates demonstrated blocked ${ }^{14} \mathrm{C}$-labeled fatty acid oxidation. Neonate I oxidized $\left[1-{ }^{14} \mathrm{C}\right]$ butyrate, -octanoate, -palmitate, and $\left[1,4-{ }^{14} \mathrm{C}\right]$ succinate to ${ }^{14} \mathrm{CO}_{2}$ at $35,60,63$, and $103 \%$ of control levels, respectively (Table III); only butyrate oxidation was significantly decreased $(P<0.05)$. Neonate II oxidized [1${ }^{14} \mathrm{C}$ ]butyrate at $64 \%$ of control levels $(P=0.07)$ and [1$\left.{ }^{14} \mathrm{C}\right]$ octanoate normally $(P=0.7)$. Neonate II's cells also oxidized $\mathrm{L}-\left[1-{ }^{14} \mathrm{C}\right]-$ and $\mathrm{L}-\left[2-{ }^{14} \mathrm{C}\right]$ leucine at 83 and $116 \%$ of control levels, respectively (data available on request). Both cell lines oxidized $\left[9,10(n)-{ }^{3} \mathrm{H}\right]$ palmitate normally; catabolism of this substrate is decreased in MCD, LCD, and the MAD.

${ }^{14} \mathrm{C}$ from radiolabeled fatty acids is incorporated into cellular protein after synthesis of ${ }^{14} \mathrm{C}$-labeled amino acids by transamination of labeled tricarboxylic acid cycle intermediates $(13,17$, 18); the amount of ${ }^{14} \mathrm{C}$ incorporated reflects the activities of both the catabolic pathway in question and the tricarboxylic

Table II. Effect of Rabbit Antiserum to Pig Kidney MCADH on Pig Liver SCADH and MCADH

\begin{tabular}{|c|c|c|c|c|}
\hline \multirow[b]{3}{*}{ Enzyme/substrate } & \multicolumn{2}{|c|}{ SCADH/butyryl-CoA } & \multicolumn{2}{|c|}{ MCADH/octanoyl-CoA } \\
\hline & \multicolumn{4}{|l|}{ Addition } \\
\hline & None & MCADH antiserum & None & MCADH antiserum \\
\hline & \multicolumn{4}{|c|}{ pmol DCIP reduced per min $\pm S E M$} \\
\hline & $154 \pm 6$ & $151 \pm 8$ & $246 \pm 9$ & $0 \pm 0$ \\
\hline
\end{tabular}

SCADH and MCADH activities were measured as previously described (8). In the indicated experiments, $5 \mu$ l of monospecific rabbit antisera to pig kidney MCADH was incubated with either pure pig liver SCADH (3.5 pmol flavin) or MCADH (1.6 pmol flavin) for $5 \mathrm{~min}$ at $30^{\circ} \mathrm{C}$ before addition of substrate. Reaction was initiated with 440 pmol ETF. The results of two separate experiments were combined. 
Table III. Radiolabeled Substrate Oxidation by Intact Fibroblasts

\begin{tabular}{llllll}
\hline & \multicolumn{1}{l}{ Substrates } \\
\cline { 2 - 6 } Cell line & {$\left[1-^{14} \mathrm{C}\right]$ Butyrate } & {$\left[1-{ }^{14} \mathrm{C}\right]$ Octanoate } & {$\left[1-{ }^{-14} \mathrm{C}\right]$ Palmitate } & {$\left[9,10(n){ }^{3} \mathrm{H}\right]$ Palmitate } & {$\left[1,4^{\left.1{ }^{4} \mathrm{C}\right] \text { Succinate }}\right.$} \\
\hline & $n m o l / m g$ protein & per $h \pm S E M$ & & & \\
Normal controls & $7.34 \pm 1.50$ & $3.31 \pm 0.72$ & $0.19 \pm 0.05$ & $0.40 \pm 0.04$ & $3.08 \pm 0.61$ \\
Neonate I & $2.59 \pm 0.48^{*}$ & $1.98 \pm 0.64$ & $0.12 \pm 0.04$ & $0.58 \pm 0.09$ & $3.18 \pm 0.92$ \\
Neonate II & $4.70 \pm 0.59^{\ddagger}$ & 2.32 & - & $0.46 \pm 0.08$ & - \\
\hline
\end{tabular}

Culture of diploid human fibroblasts, ${ }^{14} \mathrm{C}$-substrate oxidation, and ${ }^{3} \mathrm{H}$-release assays were performed as described in the text. Values from V.S.'s experiments with neonate II were normalized to the values for neonate I's studies. The number of determinations ranged from 4 to 14 for five control lines and 1 to 6 for each patient line. ${ }^{*} P<0.05$. ${ }^{\ddagger} P=0.07$.

acid cycle. In this assay system, neonates' I and II activities with $\left[1-{ }^{14} \mathrm{C}\right]$ butyrate were 29 and $56 \%$ of control, and with [1${ }^{14} \mathrm{C}$ ]octanoate, 43 and $115 \%$ of controls, respectively (Table IV). ${ }^{14} \mathrm{C}$-Incorporation from $\left[2,3-{ }^{14} \mathrm{C}\right]$ succinate was normal in both patients' cells. These results indicate defective short-chain fatty acid catabolism in both neonates and moderately defective medium-chain fatty acid catabolism in neonate $\mathrm{I}$.

Fibroblast and mitochondrial $A D H$ assays. The tritium release assay for fibroblast ADH activities uses $\left[2,3-{ }^{3} \mathrm{H}\right]$ acyl-CoAs as substrates and has been described previously $(9,12)$. Enzymatic removal of tritium from carbons 2 and 3 of the substrate forms ${ }^{3} \mathrm{H}_{2} \mathrm{O}$, which is separated quantitatively from unreacted substrate by anion exchange chromatography and lyophilization. SCADH, MCADH, and isovaleryl-CoA dehydrogenase activities in the patients' cell sonicates were measured using [2,3$\left.{ }^{3} \mathrm{H}\right]$ butyryl-, -octanoyl-, and -isovaleryl-CoAs. Neonates I and II had SCADH activities 41 and 53\% of control $(P<0.01)$, while MCADH activities were 59 and $95 \%$ of control $(P<0.1)$, respectively. Fibroblasts from the previously reported adult patient with skeletal muscle SCADH deficiency (B.H. [3]) had SCADH and MCADH activities $94 \%$ of control (Table V). The tritium release assay in mitochondrial supernatants showed SCADH and MCADH activities in neonate I to be 57 and $66 \%$ of control, similar to values in cell sonicates (data not shown).

Mitochondrial ADH activities assayed by the dye reduction method yielded analogous results in both patients (data not shown for cell sonicates). SCADH activities in neonates I and II were 37 and $47 \%$ of control, respectively $(P<0.01)$; MCADH

Table IV. ${ }^{14}$ C-Incorporation into Cellular

Protein by Intact Fibroblasts

\begin{tabular}{|c|c|c|c|}
\hline \multirow[b]{2}{*}{ Cell lines } & \multicolumn{3}{|l|}{ Substrates } \\
\hline & {$\left[1-{ }^{14} \mathrm{C}\right]$ Butyrate } & {$\left[1-{ }^{14} \mathrm{C}\right]$ Octanoate } & {$\left[2,3-{ }^{14} \mathrm{C}\right]$ Succinate } \\
\hline & \multicolumn{3}{|c|}{ nmol ${ }^{14} \mathrm{C}$ incorporated/mg protein per $h \pm S E M$} \\
\hline Normal controls & $0.94 \pm 0.09$ & $0.30 \pm 0.034$ & $1.27 \pm 0.20$ \\
\hline Neonate I & $0.27 \pm 0.03^{*}$ & $0.13 \pm 0.02^{*}$ & $0.92 \pm 0.20$ \\
\hline Neonate II & $0.52 \pm 0.07^{*}$ & $0.34 \pm 0.05$ & $1.10 \pm 0.40$ \\
\hline
\end{tabular}

${ }^{14} \mathrm{C}$-Incorporation from labeled substrates into cellular protein, and specific activities and concentrations of substrates were previously described (13). The number of determinations ranged from 16 to 32 for seven control lines and 2 to 8 for each patient line.

$* P<0.05$. activities in neonates I and II were $56 \%(P<0.01)$ and $81 \%$ of control, respectively $(P>0.2)$. Long-chain acyl-CoA dehydrogenase (LCADH) activities were $>75 \%$ of control in both patients (Table VI). The low MCADH activities in neonate I, unexpected in isolated SCADH deficiency, might be explained by an endogenous inhibitor of MCADH and/or SCADH accumulating in her cells. However, mixing neonate I and control mitochondrial supernatants yielded SCADH and MCADH activities identical to the predicted values, which argues against this possibility (data not shown). The apparent Michaelis constants $\left(K_{\mathrm{m}}\right)$ of mitochondrial MCADH towards octanoyl-CoA in both neonates I and II and controls were similar (1-3 $\mu \mathrm{M})$. In neonate $\mathrm{I}$, the apparent maximum velocity $\left(V_{\max }\right)$ with octanoyl-CoA was $60 \%$ of control, consistent with the data reported in Table VI (other data not shown).

Deficient ADH activities might result from low intramitochondrial pools of FAD in vivo. However, addition of $20 \mu \mathrm{M}$ FAD to cell or mitochondrial sonicates did not alter SCADH and MCADH activities in either neonate or controls (Table V; other data not shown). ETF activities were also normal ( $>68 \%$ of control, $P>0.2$ ) in both neonates (Table VII).

Residual butyryl-CoA dehydrogenation in both patients is

Table V. Tritium Release Assay for Fibroblast ADH Activities

\begin{tabular}{|c|c|c|c|}
\hline \multirow[b]{2}{*}{ Cell lines } & \multicolumn{3}{|l|}{ Substrates } \\
\hline & $\begin{array}{l}{\left[2,3-{ }^{3} \mathrm{H}\right] \text { Butyryl- }} \\
\mathrm{CoA}\end{array}$ & $\begin{array}{l}{\left[2,3^{-3} \mathrm{H}\right] \text { Octanoyl- }} \\
\mathrm{CoA}\end{array}$ & $\begin{array}{l}{\left[2,3-{ }^{3} \mathrm{H}\right] \text { Isovaleryl- }} \\
\text { CoA }\end{array}$ \\
\hline & \multicolumn{3}{|c|}{ pmol $^{3} \mathrm{H}$ released/min per mg protein $\pm S E M$} \\
\hline Normal controls & $139 \pm 13$ & $97 \pm 15$ & $26 \pm 4$ \\
\hline Neonate I & $57 \pm 13^{*}$ & $57 \pm 20$ & $18 \pm 3$ \\
\hline Neonate II & $74 \pm 10^{*}$ & $92 \pm 15$ & - \\
\hline B.H. (reference 3) & $131 \pm 20$ & $91 \pm 25$ & - \\
\hline
\end{tabular}

$200 \mu \mathrm{M}\left[2,3-{ }^{3} \mathrm{H}\right]$ butyryl- $(10 \mathrm{mCi} / \mathrm{mmol})$, -octanoyl- $(5 \mathrm{mCi} / \mathrm{mmol})$, and -isovaleryl-CoAs $(10 \mathrm{mCi} / \mathrm{mmol})$ were incubated with $1.5-2.5 \mathrm{mg}$ fibroblast supernatant protein, $20 \mu \mathrm{M}$ FAD, and $15 \mathrm{mM}$ phenazine methosulfate at $37^{\circ} \mathrm{C}$ for $10 \mathrm{~min}$. After passage of the reaction mixture over AG-1 anion exchange resin, duplicate samples were lyophilized at $\mathrm{pH}$ 6. The lyophilized radioactivity represents $\mathrm{H}_{2} \mathrm{O}$ formed by detritiation of the substrates (9). The number of determinations ranged from 21 to 24 for six control lines and 3 to 8 for each patient line.

$* P<0.01$. 
Table VI. Mitochondrial ADH Activities

\begin{tabular}{llcc}
\hline & \multicolumn{3}{l}{ Substrates } \\
\cline { 2 - 4 } Cell lines & Butyryl-CoA & Octanoyl-CoA & Palmityl-CoA \\
\hline & pmol DCIP reduced/min per $m g$ protein \pm SEM \\
Normal controls & $763 \pm 51$ & $1,730 \pm 166$ & $734 \pm 54$ \\
Neonate I & $281 \pm 28^{*}$ & $962 \pm 87^{\ddagger}$ & $542 \pm 58$ \\
Neonate II & $360 \pm 120^{\ddagger}$ & $1,400 \pm 200$ & $558 \pm 109$ \\
& & & \\
\hline
\end{tabular}

Butyryl-, octanoyl-, and palmityl-CoA dehydrogenase activities were measured as previously described. The number of determinations ranged from 20 to 47 for seven control lines and 4 to 22 for each patient line.

$* P<0.001$.

$\ddagger P<0.01$.

higher than one might expect in isolated SCADH deficiency and presumably results from the overlapping substrate specificities of SCADH and MCADH for butyryl CoA $(8,19-21)$. To confirm this hypothesis, we assayed fibroblast ADHs after incubation with monospecific rabbit antisera to pig kidney MCADH. MCADH antisera completely inhibited the MCADH activity towards octanoyl-CoA in both neonates and controls, thus eliminating the contribution of MCADH to butyryl-CoA dehydrogenation and permitting accurate assay of SCADH activity alone (Table VIII). In these experiments, neonates' I and II ADH activities with butyryl-CoA as substrate were 38 and $49 \%$ of control, respectively. However, after incubation with MCADH antisera, activities fell to 1 and $11 \%$ of control, respectively, with this substrate. In both patients and controls, the absolute fall in butyryl-CoA dehydrogenation was similar (250-290 pmol/mg protein per $h$ ), suggesting that $\mathrm{MCADH}$ antisera was eliminating a constant amount of butyryl-CoA dehydrogenation resulting from MCADH acting on this substrate. We conclude that MCADH activity towards butyryl-CoA explains the apparent high residual SCADH activities noted in these patients.

\section{Discussion}

The patients described here represent a new disorder of mitochondrial $\beta$-oxidation caused by a deficiency of SCADH, which catalyzes the first step of short-chain acyl-CoA catabolism. Although fibroblasts from Bennett's patient oxidized [1${ }^{14} \mathrm{C}$ ]butyrate and -hexanoate poorly (4), SCADH activity was normal in these cells (Coates, P., and D. Hale, personal communication). Thus, the metabolic defect is not yet identified in this patient. In neonate I, the clinical presentation included met-

Table VII. Mitochondrial ETF Activity

\begin{tabular}{ll}
\hline Cell lines & Specific activity \\
\hline & pmol/min per mg protein \pm SEM \\
Normal controls & $444 \pm 75$ \\
Neonate I & $314 \pm 83$ \\
Neonate II & $283 \pm 80$ \\
\hline
\end{tabular}

Mitochondria were isolated and ETF activity was measured as previously described (7). The number of determinations was 10 for five control lines and 4 to 5 for each patient line.
Table VIII. Effect of Rabbit Antiserum to Pig Kidney MCADH on Fibroblast ADH Activities

\begin{tabular}{|c|c|c|c|c|}
\hline \multirow[b]{4}{*}{ Cell lines } & \multicolumn{4}{|l|}{ Substrate } \\
\hline & \multicolumn{2}{|l|}{ Butyryl-CoA } & \multicolumn{2}{|l|}{ Octanoyl-CoA } \\
\hline & \multicolumn{4}{|l|}{ Addition } \\
\hline & None & $\begin{array}{l}\text { MCADH } \\
\text { antiserum }\end{array}$ & None & $\begin{array}{l}\text { MCADH } \\
\text { antiserum }\end{array}$ \\
\hline & \multicolumn{4}{|c|}{ pmol DCIP reduced/min per mg protein } \\
\hline Normal controls & $679 \pm 98$ & $386 \pm 62$ & $1,603 \pm 179$ & $0.0 \pm 0.0$ \\
\hline Neonate I & $259 \pm 24^{*}$ & $4 \pm 5^{\ddagger}$ & $834 \pm 190^{*}$ & $0.0 \pm 0.0$ \\
\hline Neonate II & $336 \pm 46^{*}$ & $43 \pm 43^{\ddagger}$ & $1,230 \pm 241$ & $0.0 \pm 0.0$ \\
\hline
\end{tabular}

Butyryl- and octanoyl-CoA dehydrogenase activities were measured in mitochondrial supernatants as described in Table VI. In the indicated experiments, $5 \mu \mathrm{l}$ of monospecific rabbit antisera to pig kidney

MCADH was incubated with $200-400 \mu \mathrm{g}$ mitochondrial protein for 5 min at $30^{\circ} \mathrm{C}$ before addition of substrate. Reaction was initiated with $440 \mathrm{pmol}$ ETF. The number of determinations ranged from five to six for control lines and three to five for each patient line.

$* P<0.05$.

$\ddagger P<0.001$.

abolic acidosis and excretion of ethylmalonate and methylsuccinate. Adipate excretion was never elevated, even after a medium-chain triglyceride challenge, and glutarate excretion was only mildly increased after a lysine load. Branched chain amino acid metabolites were never excreted, and no isovaleric acid derivatives were found after a leucine challenge. Subsequently, this child has grown and developed normally to age two on a normal diet. Her parents have refused further studies or clinical followup of either their daughter or themselves, making further investigation of this child difficult. Neonate II developed fatal marked metabolic acidosis and hyperammonemia on the second day of life. Excretion of ethylmalonate, butyrate, adipate, and lactate was increased.

The major common clinical feature in these two patients was their relatively high ethylmalonate excretion, with normal to slightly elevated excretion of other dicarboxylic acids. These patients seemed unlikely to suffer from MCADH or LCADH deficiencies, since the former patients excrete mainly $\mathrm{C}_{6}-\mathrm{C}_{10}$ dicarboxylic acids, and the latter have different clinical and biochemical phenotypes $(1,2,5,8)$. In a child with ethylmalonicadipic aciduria (mild variant of MAD [6]), MCT, lysine, and leucine challenges provoked excretion of metabolites derived from acyl-CoAs other than butyryl-CoA, in contrast to our observations in neonate I. Neonate II's fatal perinatal course and urinary metabolites do not exclude the diagnosis of MAD in and of themselves (5-7).

The radiolabeled substrate oxidation studies indicated an isolated defect in butyrate catabolism in both patients. $\left[{ }^{14} \mathrm{C}\right]$ Octanoate oxidation was mildly impaired in neonate $I$, while $\left[{ }^{3} \mathrm{H}\right]$ palmitate oxidation was normal in both. In MCD, LCD, and MAD patients, oxidation of this latter substrate was impaired (3-63\% of control [14]), clearly distinguishing them from these two neonates. Tritium release and dye reduction $\mathrm{ADH}$ assays in cell and mitochondrial supernatants revealed decreased SCADH activities in both neonates, and lowered MCADH activity in neonate $\mathrm{I}$; in contrast, we found normal ADH activities 
in the lipomyopathy patient of Turnbull et al. (3). Although we readily demonstrated deficient SCADH activity in our patients, the residual enzymatic activities with butyryl-CoA was larger than anticipated for an isolated enzymatic defect. The high residual SCADH activities in these neonates probably resulted from overlapping chain length substrate specificities of human fibroblast ADHs, in analogy to other mammalian ADHs. While highly purified rat liver MCADH is relatively specific for $\mathrm{C}_{6}-\mathrm{C}_{8}$ acylCoAs, with little activity toward $\mathrm{C}_{4}$ substrates (19-21), bovine MCADH and LCADH both show some activity towards butyrylCoA (20).

While the chain length specificities of human ADHs are not known, we and others have evidence that human fibroblast MCADH can dehydrogenate butyryl-CoA. In patients with isolated MCADH deficiency ( $<10 \%$ of control activity), fibroblast apparent SCADH activities are as low as $42 \%$ of control $(1,8$, 9), presumably reflecting the loss of MCADH activity towards butyryl-CoA. We inhibited MCADH with monospecific antisera, thereby removing its contribution to butyryl-CoA dehydrogenation and accurately defining butyryl-CoA dehydrogenation of SCADH. Octanoyl-CoA dehydrogenation by MCADH was completely inhibited in both neonates and controls by MCADH antisera, demonstrating that $43 \%$ of butyryl-CoA dehydrogenation in normal fibroblasts is catalyzed by MCADH. In the presence of MCADH antisera, neonates' I and II SCADH activities fell to 1 and $11 \%$ of control, respectively.

While FAD is the ionically bound cofactor of the three straight-chain ADHs, with SCADH binding FAD more tightly than MCADH or LCADH (21), FAD addition did not increase SCADH activity in either neonate or controls. Although neonate I's cells had decreased MCADH activity under all assay conditions, mixing experiments did not reveal an endogenous MCADH inhibitor in this cell line. Crotonase addition did not alter mitochondrial SCADH and MCADH activities in neonate I, suggesting that no inhibitory 3-ketoacyl-CoAs were accumulated (data not shown). Lowered MCADH activity in neonate I could also result from a mutant MCADH enzyme with an altered $K_{\mathrm{m}}$ for medium-chain substrates and no activity towards butyrylCoA. However, this patient's apparent $K_{\mathrm{m}}$ of MCADH for octanoyl-CoA was identical to control, while the lowered $V_{\max }$ for this substrate suggested decreased amounts of the active enzyme. As cell lines are not available from neonate I's parents, we cannot exclude the possibility of this patient being heterozygous for MCADH deficiency, as well as homozygous for SCADH deficiency. Neonate I may also have constitutively lowered activities of $\beta$-oxidation and its component enzymes, as MCADH, LCADH, isovaleryl-CoA dehydrogenase and ETF activities all ranged from 56 to $74 \%$ of control, depending on the enzyme considered. While neonate II clearly has isolated SCADH deficiency, we cannot explain the marked difference in clinical manifestations between these two patients. Further investigations of both will require further clinical, immunochemical, biosynthetic, and molecular studies.

While these two patients express SCADH deficiency in cultured fibroblasts, it is of interest that the other published patient has muscular SCADH deficiency (3). Although this patient's fibroblasts oxidized [U- $\left.{ }^{14} \mathrm{C}\right]$ palmitate normally and have normal SCADH and MCADH activities (Table V), she may be deficient in an SCADH isoenzyme expressed only in muscle tissue. Further study of this and similar patients may extend our understanding of $\beta$-oxidation isoenzymes in man.

\section{Acknowledgments}

We thank Dr. K. Tanaka for generously supplying $2,3-{ }^{3} \mathrm{H}$-fatty acids, Dr. C. Hall for pig liver ETF, MCADH, and SCADH, and Dr. C. Thorpe for pig kidney MCADH; Dr. P. Coates, Dr. D. Hale, and Dr. D. Turnbull for B. H.'s fibroblasts, Dr. C. Costello for mass spectrometry of the organic acids in neonate II, Ms. B. Norbeck and T. Lutz for technical assistance, and Ms. B. McKean for preparation of the manuscript.

This work was supported by grants from National Institutes of Health (NIH) (HD-00380; AM-33289), the National Foundation March of Dimes (5-297; 1-876), a grant from the Muscular Dystrophy Association (all to Dr. Rhead), and by NIH grants HD-04608 (to Dr. Sweetman) and NS-05096 (to Dr. Shih).

\section{References}

1. Coates, P. M., D. E. Hale, C. A. Stanley, B. E. Corkey, and J. A. Cortner. 1985. Genetic deficiency of medium-chain acyl Coenzyme A dehydrogenase: studies in cultured skin fibroblasts and peripheral mononuclear leukocytes. Pediatr. Res. 19:671-676.

2. Hale, D. E., M. L. Batshaw, P. M. Coates, F. E. Frerman, S. I. Goodman, I. Singh, and C. A. Stanley. 1985. Long-chain acyl coenzyme A dehydrogenase deficiency: an inherited cause of nonketotic hypoglycemia. Pediatr. Res. 19:666-671.

3. Turnbull, D. M., K. Bartlett, D. L. Stevens, K. G. M. M. Alberti, G. J. Gibson, M. A. Johnson, A. J. McCullock, and H. S. A. Sherratt. 1984. Short-chain acyl-CoA dehydrogenase deficiency associated with a lipid storage myopathy and secondary carnitine deficiency. $N$. Engl. J. Med. 311:1232-1236.

4. Bennett, M. J., R. G. F. Gray, D. M. Isherwood, N. Murphy, and R. J. Pollitt. 1985. The diagnosis and biochemical investigation of a patient with a short chain fatty acid oxidation defect. J. Inherited Metab. Dis. 2(Suppl. 8):135-136.

5. Gregersen, N. 1985. The acyl-CoA dehydrogenation deficiencies. Scand. J. Clin. Lab. Invest. 45(Suppl. 174):1-60.

6. Mantagos, S., M. Genel, and K. Tanaka. 1979. Ethylmalonicadipic aciduria: in vivo and in vitro studies indicating deficiency of activities of multiple acyl-CoA dehydrogenases. J. Clin. Invest. 64:15801587.

7. Amendt, B. A., and W. J. Rhead. 1986. The multiple acyl-CoA dehydrogenation disorders, glutaric aciduria type II, and ethylmalonicadipic aciduria. Mitochondrial fatty acid oxidation, acyl-CoA dehydrogenase, and electron transfer flavoprotein activities in fibroblasts. J. Clin. Invest. 78:205-213.

8. Rhead, W., B. Amendt, K. Fritchman, and S. Felts. 1983. Dicarboxylic aciduria: deficient $\left[1-{ }^{14} \mathrm{C}\right]$ octanoate oxidation and medium chain acyl-CoA dehydrogenase activity in fibroblasts. Science (Wash. DC). 221: 73-75.

9. Amendt, B. A., and W. J. Rhead. 1985. Catalytic defect of medium chain acyl coenzyme A dehydrogenase deficiency. Lack of both cofactor responsiveness and biochemical heterogeneity in eight patients. J. Clin. Invest. 76:963-969.

10. Duran, M., G. Mitchell, J. de Klerk, J. B. de Jager, M. Hofkamp, L. Bruinvis, D. Ketting, J. M. Saudubray, and S. Wadman. 1985. Octanoic acidemia and octanoylcarnitine excretion with dicarboxylic aciduria due to defective oxidation of medium-chain fatty acids. J. Pediatr. 107:397404.

11. Sweetman, L. 1984. Qualitative and quantitative analysis of organic acids in physiologic fluids for diagnosis of the organic acidurias. In Abnormalities in Amino Acid Metabolism in Clinical Medicine. W. L. Nyhan, editor. Appleton-Century-Crofts, East Norwalk, CT. 419453.

12. Rhead, W. J., C. L. Hall, and K. Tanaka. 1981. Novel tritium release assays for isovaleryl-CoA and butyryl-CoA dehydrogenase. J. Biol. Chem. 256:1616-1624. 
13. Rhead, W. J., A. Moon, V. Roettger, and K. Henkle. $1985 .{ }^{14} \mathrm{C}-$ labelled substrate catabolism by human diploid fibroblasts derived from infants and adults. Biochem. Med. 34:182-188.

14. Moon, A., and W. Rhead. 1987. Complementation analysis of fatty acid oxidation disorders. J. Clin. Invest. 79:59-64.

15. Rhead, W. J., and B. A. Amendt. 1984. Electron transferring flavoprotein deficiency in the multiple acyl-CoA dehydrogenation disorders, glutaric aciduria type II and ethylmalonic-adipic aciduria. $J$. Inherited Metab. Dis. 7:99-100.

16. Thorpe, C., R. Matthews, and C. Williams. 1979. Acyl-Coenzyme A dehydrogenase from pig kidney. Purification and properties. Biochemistry. 18:331-337.

17. Wendel, U. 1980. Prenatal detection of defects in propionate metabolism. Clin. Chim. Acta. 108:475-477.

18. Willard, H., J. Mellman, and L. Rosenberg. 1978. Genetic com- plementation among inherited deficiencies of methylmalonyl-CoA mutase activity: evidence for a new class of human cobalamin mutant. Am. J. Hum. Genet. 30:1-13.

19. Ikeda, Y., C. Dabrowski, and K. Tanaka. 1983. Separation and properties of five distinct acyl-CoA dehydrogenases from rat liver mitochondria: identification of a new 2-methyl branched chain acyl-CoA dehydrogenase. J. Biol. Chem. 258:1066-1076.

20. Davidson, B., and H. Schulz. 1982. Separation, properties, and regulation of acyl coenzyme A dehydrogenases from bovine heart and liver. Arch. Biochem. Biophys. 213:155-162.

21. Ikeda, Y., K. Okamura-Ikeda, and K. Tanaka. 1985. Purification and characterization of short-chain, medium-chain and long-chain acylCoA dehydrogenases from rat liver mitochondria. J. Biol. Chem. 260: 1311-1325. 